
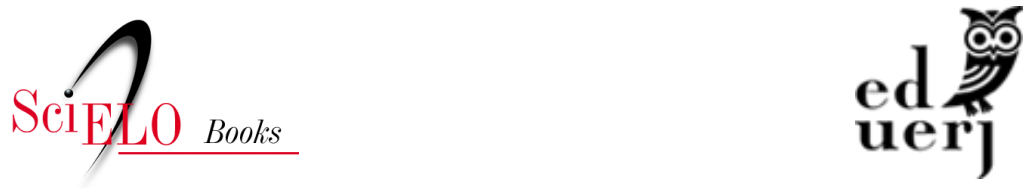

\title{
Capítulo 4. Autoscopia no processo formativo de professores no uso da Comunicação Alternativa
}

\author{
Carla C. Marçal y Guthierrez \\ Cátia Crivelenti de Figueiredo Walter
}

\section{SciELO Books / SciELO Livros / SciELO Libros}

GUTHIERREZ, C. C. M., and WALTER, C. C. F. Autoscopia no processo formativo de professores no uso da Comunicação Alternativa. In: NUNES, L. R. D. P., ed. Autoscopia: uma ação reflexiva sobre a prática docente [online]. Rio de Janeiro: EDUERJ, 2020, pp. 113-134. ISBN: 97865-87949-10-9. https://doi.org/10.7476/9786587949109.0006.

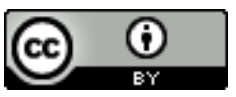

All the contents of this work, except where otherwise noted, is licensed under a Creative Commons Attribution 4.0 International license.

Todo o conteúdo deste trabalho, exceto quando houver ressalva, é publicado sob a licença Creative Commons Atribição 4.0.

Todo el contenido de esta obra, excepto donde se indique lo contrario, está bajo licencia de la licencia Creative Commons Reconocimento 4.0. 


\title{
Capítulo 4 \\ Autoscopia no processo formativo de professores no uso da Comunicaçáo Alternativa
}

\author{
Carla C. Marçal y Guthierrez \\ Cátia Crivelenti de Figueiredo Walter
}

\section{Introduçáo}

Ao longo dos anos, a formação de professores no Brasil, principalmente, ganha credibilidade quando articulada aos "problemas de aprendizagem", conforme nos conferem os estudos de Antônio Nóvoa (2009). Contudo, pesquisas comprovam a importância da formação continuada e o quanto a troca de saberes entre os profissionais da educação de várias redes educativas contribuem para o crescimento do ensino colaborativo.

A formação continuada tem sido investigada por diversos pesquisadores no Brasil, segundo a pesquisadora Longarezi (2007). Ela afirma que os estudos têm enfoque principalmente na formação continuada de professores, ou seja, nas açôes formativas que sucedem a formação inicial do professor. Nunes (2009) sugere que um importante fator que pode prejudicar o processo de inclusão é a ausência de uma formação inicial e continuada adequada. Assim como Schirmer (2012) ressalta que uma formação adequada pode oferecer ao professor - tanto o que atuará na rede de ensino comum 
com o da especializada -, entre outras coisas, práticas e conhecimentos consistentes sobre o processo de ensino e de aprendizagem.

A temática formação é considerada, por muitos autores, como fator importante para o sucesso dos profissionais da educação, sendo tema de muitas pesquisas desenvolvidas e onde é possível observar mudanças significativas na prática dos profissionais. Togashi et al. (2017) revelam que a formação continuada em serviço é fundamental para que o professor se torne cada vez mais habilitado e seguro e, dessa forma, possa desenvolver a profissão docente. Segundo Barros e Moraes (2002), as inquietaçóes colocam em questão os modos hegemônicos de formação do/a professor/a, apostando em práticas que se configurem em múltiplas formas de ação, como produção de saberes e de práticas sociais que promovam a formação de sujeitos de uma sociedade.

Ocorre, no entanto, que, algumas vezes, durante a formação, a teoria é compreendida pelos professores. Ainda assim, muitos deles saem do curso sem saber o que fazer e como atuar, de fato, na sala de aula. Essas questôes precisam de valorização por parte dos "formadores de formadores" na busca de uma formação mais eficaz e funcional no cotidiano escolar. Muito valem os estudos cognitivos necessários a toda formação, mas os professores e futuros professores ainda estão desejosos por saber o que fazer no cotidiano de sua sala de aula. É preciso ficar claro para os formadores que o ato de ensinar tem especificidades diferentes das do ato de aprender. $\mathrm{O}$ momento agora é o da busca pelas práticas baseadas em evidências, nas quais é possível confrontar as análises e os resultados publicados como eficazes nos dias de hoje, transformá-las em propostas e viabilizá-las; caso contrário, só nos restará constatar os fracassos (Gatti, 1992, p. 74).

Sendo assim, a formação de professores deve assumir um componente prático voltado para a aprendizagem dos alunos e os estudos de casos concretos. Já é tempo de se abandonar a ideia de que a característica principal do professor se define, sobretudo, pela 
capacidade de transmitir um determinado saber. Ora, essa ideia simplista, acrescida do pensamento de que ensinar é muito fácil, tem desprestigiado a profissão docente. Sabemos, entretanto, que o que caracteriza a carreira do professor é a sua prática desenvolvida utilizando teoria e método, que faz o conhecimento docente acontecer (Nóvoa, 2009, p. 5).

Compreende-se que a formação docente precisa ter um caráter reflexivo, em que o professor seja capaz de pensar sua prática por meio da observação e, a partir disso, atribuir sentidos e significados de suas açóes em sala de aula. Dessa maneira, a autoscopia tem sido um procedimento que nos permite essa reflexão e, portanto, o professor reflexivo.

A formação de professores não pode, pois, ser pensada numa perspectiva de simples transmissáo, mas com vistas a instrumentar o aluno - futuro cidadão - para melhor compreender a realidade em que se encontra, possibilitando-lhe uma atuação consciente sobre ela (Magalhães, 2009). Por isso, acredita-se na técnica da autoscopia como uma excelente ferramenta, para que o professor se observe com o distanciamento necessário para refletir sobre suas posturas e, portanto, reformular suas práticas docentes e o planejamento de suas aulas. Segundo Leite (2012, p. 358);

A autoscopia é um procedimento de coleta de dados conhecido como confrontação de si na tela: são realizadas sessóes de gravação do comportamento do sujeito (ex: relaçôes em sala de aula) e, após edição da fita, o sujeito é colocado em uma situação para observar o material gravado, sendo estimulado verbalmente pelo pesquisador para emitir comentários em função dos objetivos da pesquisa.

Assim, pensamos essa formação como um processo integrado ao dia a dia dos professores e da escola, e "não como uma função que intervém à margem dos projetos profissionais e organizacionais" (Pereira, 2002). 
Nos últimos anos, tem sido crescente a entrada de estudantes com TEA nas escolas comuns e cada vez mais os desafios vão surgindo nesse cotidiano. Esse crescente número de alunos com deficiência e TEA tem demandado à equipe escolar, e principalmente aos professores que atuam no Atendimento Educacional Especializado (AEE) e no ensino comum, conhecimento específico sobre o assunto.

A formaçáo docente tem sido uma demanda e uma urgência nos cotidianos das escolas. $\mathrm{E}$ as experiências de autoscopia têm trazido bons resultados na prática e na ação docente, mediante a própria observação com a intervenção. Assim, trazemos um relato de experiências sobre autoscopia, a partir de um programa de formação continuada para professores do $\mathrm{AEE}$ - no uso da Comunicação Alternativa (CA) com alunos com TEA.

Esse programa faz parte de uma pesquisa de doutorado que surge a partir de uma demanda em uma escola pública na cidade do Rio de Janeiro. Desde 2016, a entrada de estudantes com TEA sem fala articulada e/ou não verbalizados tem crescido e, com isso, os desafios dos docentes também aumentam.

No cotidiano dessa escola, os estudantes com TEA e sem fala funcional são inseridos com foco na socialização e na escolarização; no entanto, observou-se a não utilização dos cartóes de Comunicação Alternativa. Os questionamentos vão surgindo e o processo de inclusáo vai se tornando algo cada vez mais complexo. Como se dá a comunicação desses estudantes? Com quem se comunicam? Quando a professora do AEE não está na escola, quem oferece o suporte na comunicação desse aluno? E o estudante que se encontra há três anos na escola, como se comunica? Diante dessa demanda, surge a necessidade de uma investigação que possa responder a tais questôes e que busque alternativas de comunicação que sejam eficazes no processo de interaçáo desses alunos com TEA.

Vale lembrar que o AEE foi regulamentado pelo Decreto N.o 6571, de 2008, que reestrutura a Educação Especial, consolida 
diretrizes e açôes já existentes à Educação Inclusiva e destina recursos do Fundo da Educação Básica (FUNDEB) ao atendimento de necessidades educacionais especiais (Figueiredo, 2010, p. 33). O AEE tem por objetivo integrar a proposta pedagógica da escola, envolvendo a família e realizando articulaçóes com outras políticas públicas. Podemos considerar como um conjunto de recursos pedagógicos e de acessibilidade organizados de forma complementar à formação dos alunos no ensino regular. Dessa maneira, questiona-se muito a ação dos professores do AEE perante as condiçóes impostas pela política de inclusão, sobretudo quando estes são responsáveis pelas adaptaçóes necessárias mediante as necessidades dos alunos com deficiência.

Diante dessas demandas, pensar a Comunicação Alternativa é algo urgente e necessário, pois constitui-se em área da Tecnologia Assistiva (Bersch, 2007) com um duplo propósito: promover e suplementar a fala ou garantir uma forma alternativa, se o indivíduo não se mostra capaz de desenvolvê-la (Nunes, 2013), bem como oferecer estratégias de comunicação aos seus interlocutores (Nunes, 2007 e 2009; Schrimer, 2012). Ora, a CA se caracteriza por um conjunto de métodos e técnicas que facilitam a comunicação, ampliando as possibilidades de troca, de experimentação individual e de relacionamento com o outro. O uso dos cartóes de Comunicação é frequente por serem recursos simples para apresentar os símbolos gráficos ou fotografias em um espaço mais compacto. Num estudo desenvolvido por Walter e Nunes (2013), os professores receberam um curso de formaçáo teórico-prático sobre o emprego do PECS-Adaptado (Walter, 2000), sobre o uso de um sistema de Comunicação Alternativa por intercâmbio de figuras e que é especialmente destinado aos alunos com TEA. Os resultados mostraram que a maioria dos professores apresenta intenção de se comunicar melhor com seus alunos, expressando, contudo, necessidade de suporte de professores do AEE e consideraram ainda que a CA deve 
ser introduzida inicialmente na sala de AEE e, posteriormente, na sala de aula regular.

Walter (2009, p. 98) traz uma discussão no curso de formação inicial dos alunos de Pedagogia com atuação na área de Tecnologia Assistiva (TA), com ênfase na Comunicação Alternativa e Ampliada (CAA), na qual reflete a partir de uma proposta de abordagem problematizadora com o uso do PECS-Adaptado e afirma:

O programa de comunicação alternativa através do PECS-Adaptado se inicia com atos funcionais que coloca a criança em contato com reforçadores naturalmente eficazes, representados por itens mais desejados e necessários, selecionados previamente pelos familiares e pelo professor. Uma lista de itens preferenciais da criança é fornecida pelos pais antes de iniciar o treinamento das fases do PECS-Adaptado, com o objetivo de conhecer os itens mais significativos e relevantes de cada aluno. As figuras utilizadas no PECS e no PECS-Adaptado podem ser desenhos, clip-arts, encartes ou figuras de softwares específicos de comunicação alternativa. No PECS-Adaptado foram utilizados os pictogramas contidos no software PCS (Picture Communication Symbols).

Com a intenção de aproximação e diálogo com as professoras sobre suas práticas, é importante filmar o dia a dia de suas salas de aula, buscando compreender melhor como são realizadas as interaçóes com seus alunos. Para isso, utiliza-se a autoscopia como um recurso para a análise da ação docente e também para observar os comportamentos comunicativos e a interação com os alunos com TEA.

A autoscopia vale-se do recurso de videogravação de uma prática, visando à análise e à autoavaliação por um ou mais protagonistas dessa prática. Por meio da videogravação, objetiva-se apreender as açôes do ator (ou atores), o cenário e a trama que compóem uma situação. $\mathrm{O}$ material videogravado é submetido a sessôes de análise a posteriori da ação, as quais se destinam à apreensão do processo 
reflexivo do ator (ou atores), por intermédio de suas verbalizaçóes durante a análise das cenas videogravadas (Sadalla et al., 1996).

Pensando nesse cotidiano, como contribuir para a comunicação desses estudantes? Como contribuir para a formaçáo dessas professoras no uso da Comunicação Alternativa? Será que a não utilização dos cartôes de CA se dá pela falta de formação? A fim de dialogar com todos esses questionamentos, foi elaborada essa proposta que foi a criação de um programa de formação de professores no uso da CA, utilizando a autoscopia como ferramenta de reflexão e na busca de mudanças nas práticas pedagógicas. Assim, o presente capítulo tem o propósito de relatar a experiência do uso da autoscopia na formação continuada de professores do AEE no uso da Comunicação Alternativa, mais especificamente na aplicação do PECS-Adaptado por alunos com diagnóstico de TEA, sobretudo sem fala funcional.

\section{Método}

Participantes - participaram do estudo: Júlio, ${ }^{1}$ Marcos, ${ }^{2}$ duas professoras e três assistentes de pesquisa e a intervencionista.

A primeira fase do estudo constitui-se na formação continuada de cinco professoras mestras e doutoras de uma Universidade Pública no RJ, três alunas de licenciatura e bolsistas de projetos desenvolvidos na mesma universidade e dois estudantes com TEA. Dessas cinco professoras, duas foram sujeitos de pesquisa, juntamente com seus dois estudantes com TEA sem fala funcional.

Professoras - a professora A é fonoaudióloga, pós-doutora em Educação Especial e tem experiência em sala de aula e clínica. A professora B é pedagoga e mestre em Educação. Atua na instituição de ensino há mais de cinco anos.

\footnotetext{
1 Nome fictício para preservar a identidade do estudante.

2 Nome fictício para preservar a identidade do estudante.
} 
Estudantes - o estudante A (Júlio) tem TEA severo e sem fala funcional, tem seis anos de idade, tem atendimento fonoaudiológico e psicopedagógico e cursa o $1 .^{\circ}$ ano do Ensino Fundamental. O estudante B (Marcos) tem TEA severo e sem fala funcional, tem nove anos de idade, tem atendimento fonoaudiológico e cursa o 3. ${ }^{\circ}$ ano do Ensino Fundamental.

Assistentes de pesquisa - três estudantes do $7 .^{\circ}$ período do curso de Biologia e bolsistas de projeto de extensão e estágio interno complementar da Universidade do Estado do Rio de Janeiro. Foram responsáveis pelas gravaçôes.

Local - o estudo foi realizado na sala de Atendimento Educacional Especializado (AEE) de uma escola pública, estruturada com mesas e cadeiras, computadores, impressora e armários com livros/jogos didáticos-pedagógicos.

Materiais e equipamentos - 1) uma filmadora digital; 2) uma câmera fotográfica; 3) pictogramas do ARASSAC, ${ }^{3}$ 4) atividades pedagógicas realizadas com imagens de bichos de jardins; 5) computador/notebook; 6) plastificadora; e 7) impressora.

Instrumentos - foram utilizados questionários para descrever o perfil e o conhecimento das professoras acerca da Comunicação Alternativa; diário de campo, onde foram registradas as impressôes e anotaçóes da pesquisadora (primeira autora).

Programa de Formação Continuada com Autoscopia - no programa de capacitação, as professoras foram ensinadas a empregar o PECS-Adaptado (Walter, 2000) em suas cinco fases. ${ }^{4}$ Concomi-

3 Sistema gráfico gratuito, desenvolvido pelo Governo de Aragon, Espanha, disponível pelo site: http://www.catedu.es/arasaac/descargas.php\#select.

4 O PECS-Adaptado (Walter, 2000) é um programa de Comunicação Alternativa por meio de intercâmbio de figuras baseado no PECS - Picture Exchange Communication Symbols (Bondy e Frosty, 1994), que sofreu adaptaçóes na sua forma de aplicação e registro, com estilo mais latino. As adaptaçóes propostas foram fundamentadas na metodologia do Currículo Funcional Natural (Leblanc, 1991) e apresentadas de forma diferenciada do programa original. Assim, o PECS-Adaptado é dividido em cinco fases de aplicação, sendo indicado para pessoas com autismo, ou com outros déficits severos 
tantemente ao treinamento do PECS-Adaptado, elas foram instruídas a utilizar estratégias naturalísticas de ensino, contemplando o uso da CA. Deu-se ênfase ao arranjo ambiental que se caracteriza pela organização física do ambiente, onde os pictogramas (construídos durante a formação) são colocados próximos ao aluno e representam objetos de seu interesse, dispostos em seu campo visual, mas fora de seu alcance. Utilizou-se a estratégia de Mando com CA, em que as professoras formulam perguntas e comentários, além das solicitaçóes, utilizando a linguagem oral e o sistema pictográfico de comunicaçáo. Ao final de cada encontro, foi separado um momento para a realização da autoscopia a partir das gravaçóes realizadas das professoras com os estudantes em sala de aula.

Delineamento de pesquisa - uma pesquisa quase-experimental do tipo A-B ( $\mathrm{A}$ - linha de base, B - intervenção) foi realizada neste estudo. Esse delineamento permite que o pesquisador introduza e retire, sistematicamente e repetidas vezes, os procedimentos de intervenção - variável independente (Nunes e Walter, 2016).

Variáveis - variável independente (VI) foi a autoscopia durante a formaçáo continuada com as professoras, e, para as variáveis dependentes (VD), foram organizadas as seguintes categorias: a) estudante se comunica com a professora; b) professora favorece a comunicação; c) uso da CA pelo estudante; e d) uso da CA pelas professoras. Esse estudo se desenvolveu a fim de verificar como a VI modifica as VDs.

Definição das variáveis dependentes:

a. Estudante se comunica com a professora - observaram-se as diversas formas de comunicação do estudante com a professora.

na comunicação oral, que apresentam dificuldades para iniciar um diálogo de forma espontânea ou inabilidades sociais graves. 
122 Autoscopia: uma ação reflexiva sobre a prática docente

b. Professora favorece a comunicação - ocorria quando a professora apresentava os cartóes de CA, a fim de favorecer a comunicação.

c. Uso da CA pelo estudante - ocorria quando o estudante utilizava os CAs para comunicar-se com a professora.

d. Uso da CA pelas professoras - observou-se a prática da professora, em sala de aula, sobretudo no uso dos CAs, seja para comunicação com estudante ou para favorecimento dos conteúdos pedagógicos.

Procedimentos gerais - a pesquisa teve aprovação do Comitê de Ética e da instituiçáo de ensino (parecer consubstanciado do CEP n. ${ }^{\circ}$ 3.236.623). Os participantes foram contatados pela pesquisadora, que apresentou o Termo de Consentimento Livre e Esclarecido (TCLE).

Procedimentos específicos - os procedimentos foram empregados em três etapas:

I. Linha de Base (LB): procedeu-se da seguinte maneira: as assistentes da pesquisa filmavam o dia a dia das professoras com os estudantes com autismo durante vinte minutos em cada sessão. Foram realizadas três sessóes de linha de base, a fim de verificar o uso dos cartôes de CA.

II. Intervenção com a Formação Continuada Docente: essa etapa teve início após a linha de base. As professoras foram instruídas pela pesquisadora sobre como utilizar o PECS-Adaptado associado às estratégias naturalísticas de ensino. Essa formação continuada teve quatro encontros de 5 horas, totalizando 20 horas, e fez-se autoscopia com as docentes com quatro sessōes de 20 minutos. Os encontros tiveram as seguintes temáticas: 
1 encontro: conceito de Transtorno do Espectro Autista (TEA) e como organizar o trabalho pedagógico com este público-alvo;

$2^{\circ}$ encontro: uso do painel de rotina;

3o encontro: CAA para alunos com TEA (PECS-Adaptado);

$4^{\circ}$ encontro: elaboração de cartóes de CAA.

III. Intervenção aplicando a CA por meio do programa PECS-Adaptado: essa etapa teve início com a fase 1 do PECS-Adaptado. Nesse momento, as professoras foram instruídas a utilizar os itens que os estudantes mais tinham interesse para dar início à fase. A professora A utilizou o momento do lanche para a solicitação por meio da troca dos cartóes de CA, e a professora B utilizou o momento de jogos no computador.

Foram vinte sessóes conduzidas, durante seis meses, entre linha de base e intervenção. Foram realizadas três sessôes de linha de base e dezessete de intervenção. Dessas dezessete sessôes de intervençáo, quatro foram destinadas à formaçáo continuada com as professoras. Todas as sessões foram filmadas, transcritas e submetidas à análise de conteúdo. Assim como o diário de campo, questionários e materiais produzidos ao longo da formação, como os cartôes foram produzidos a partir dos interesses dos estudantes e alguns materiais pedagógicos.

Procedimento de coleta e análise de dados - os dados foram coletados por meio de filmagens e registros em diário de campo e questionários utilizados para coletar informaçóes durante a linha de base e intervenção. A análise dos dados foi referente à performance das professoras nas formas de comunicaçáo utilizadas com 
os alunos com TEA, mediante o uso de cartôes de CA, assim como as variações no comportamento comunicativo dos alunos com as professoras durante sua interação nas atividades acadêmicas. No presente estudo, serão descritos os resultados referentes ao comportamento dos professores durante o processo de autoscopia, as reflexões e as orientaçóes referentes ao uso dos cartóes de CA.

Medidas de fidedignidade - as sessóes foram codificadas por três assistentes de pesquisa, que receberam treinamento antes do início do estudo. Com o objetivo de avaliar o índice de fidedignidade das categorias, foram analisadas $25 \%$ das sessóes nas fases de LB e intervenção. $\mathrm{O}$ índice de concordância variou entre $70 \%$ e $95 \%$, indicando adequada fidedignidade, de acordo com Fagundes (2000).

\section{Resultados e discussão}

Nas três sessões de linha de base, verificou-se o não uso dos cartôes de Comunicação Alternativa pelas professoras e nem pelos alunos, mesmo com a disponibilidade de cartóes de CA na sala de aula. As professoras tentavam uma comunicação com os estudantes a partir de suas linguagens corporais e utilizavam somente a fala para se comunicarem com os alunos com TEA.

Durante as sessóes de intervenção, as professoras foram orientadas a utilizarem os cartóes de CA. Para isso, quatro sessóes foram voltadas para a formação continuada de professores no uso da CA e nas orientaçóes do uso do programa PECS-Adaptado.

Durante os encontros de formação, foi reservado um determinado momento para a realização da autoscopia. As professoras puderam assistir aos vídeos sobre suas aulas e as atividades desenvolvidas com seus respectivos alunos com TEA. Eram destacados trechos considerados de grande importância para a reflexão e o diálogo com as professoras. Algumas açóes foram sugeridas após as observações dos vídeos para o favorecimento da comunicação 
dos estudantes, sobretudo com as professoras e os pares dos alunos com TEA. Foram proporcionados momentos de diálogo a partir da própria ação docente e foi estimulada uma prática docente reflexiva, por meio da observação dos trechos selecionados nos vídeos. Serão destacados alguns relatos das professoras para ilustrar os acontecimentos importantes do processo de reflexão.

Em uma sessão de autoscopia, o estudante Júlio se retira da sala de aula, parece agoniado. A professora A o segue e pergunta: "Você quer beber água? Quer ir ao banheiro?". O estudante coloca as máos no ouvido e fica próximo à escada, como se quisesse ir embora. A professora volta à sala de aula, pega um livro e tenta atraí-lo para retornar à sala de aula.

Durante a autoscopia, a pesquisadora questiona a professora:

Se você tivesse os cartóes de CA com a rotina dele, será que diria para você sobre seu desejo? Porque ele demonstra que quer algo ou pelo menos que não quer ficar em sala com a turma.

A professora A fica em silêncio e balança a cabeça, parecendo duvidosa. A pesquisadora faz um outro questionamento:

Não foi perigoso voltar na sala de aula para pegar um livro e deixá-lo sozinho próximo à escada?

\section{Professora A:}

Sim, mas não tínhamos inspetor naquele dia no corredor [...]

Nesse momento, foi realçado pela pesquisadora o quanto o dia a dia na escola pública é desafiador. A precariedade e a ausência de profissionais da educação, como os inspetores, interferem diretamente na ação docente. Então, a pesquisadora sugere uma prancha com os cartóes de CA contendo imagens que representam a rotina e interesses do estudante, para que a comunicaçáo fique 
mais contextualizada, ou seja, para que haja interação entre eles durante as atividades propostas no dia. A professora concorda, e, assim, foram confeccionados os cartóes de CA durante esse período.

Vale ressaltar que, durante essa formação, três estudantes de licenciatura da UERJ, que são bolsistas de projetos na perspectiva inclusiva desenvolvidos nessa instituição, contribuíram na confecção dos materiais. Elas construíram pranchas com cartóes de CA para as professoras e estudantes e ainda confeccionaram, juntamente com a pesquisadora, murais com cartóes de CA para a sala do AEE. $\mathrm{Na}$ linha de base, foi observado que não havia nenhuma proposta de CA na sala de AEE da escola e na sala de aula regular em questão.

Durante os encontros de formação continuada, verificou-se que a autoscopia é um excelente instrumento de formação, pois foi possível uma avaliação das próprias condutas, mas também a autonomia do pensar e do fazer das docentes.

Silva (2016) diz que a autoscopia é um meio eficaz no processo de formação continuada e coloca os professores em posição de recomeço, de forma que eles assumam a postura de rever suas práticas e percebam a necessidade de estar em contínuo processo de aprendizagem. Segundo a autora, a autoscopia é uma janela quando for o meio que possibilita o professor a sair de si e a olhar o externo que está ao seu redor, de modo que ele não seja mais o único ser do universo, passando a considerar e a significar o mundo à sua volta. No presente estudo foi possível observar que as professoras modificaram suas práticas a partir da reflexão e observação das suas atividades e ações com os alunos com TEA, em que o processo de autoscopia foi o grande aliado para tal mudança.

Por meio da autoscopia foram analisados os comportamentos e atitudes das professoras e dos alunos com TEA quanto ao uso da CA. O uso dos cartôes de CA foi sugerido em diferentes momentos e, durante suas práticas, faziam as modificaçóes necessárias na medida do possível. 
No primeiro dia em que foi realizada a autoscopia, as professoras pareciam tensas e/ou preocupadas. Fato esse destacado por Rosa-Silva et al. (2009), que mostra certo constrangimento inicial das professoras por serem filmadas e analisadas durante o processo de formaçáo. Mas, no decorrer dos encontros, esses momentos foram prazerosos e de grande aprendizado, passando a ser mais desejados pelas professoras ao perceberem que estavam aprendendo muito com as reflexôes e as orientaçóes da pesquisadora.

A professora $\mathrm{B}$ teve mais dificuldades quanto ao uso dos cartôes de CA. Ela acompanhou o estudante há três anos e nunca os havia utilizado. Essa dificuldade se deu pelo fato de ela compreender o estudante em muitas de suas açóes, devido ao tempo de convivência. E, quando ela não estava presente, parecia ficar difícil para os outros professores e os pares compreenderem o estudante. Em uma das sessóes de autoscopia, o estudante B se jogou no chão no momento da roda com a turma; a professora não estava próxima a ele e ficou tentando, de longe, chamá-lo para participar da roda.

Pesquisadora: "Por que você não está próxima a ele?"

Professora B: "Ele já está acostumado a ficar na roda, e eu quero dar independência para ele [...]"

Pesquisadora: "E se você se aproximasse dele, para que o trouxesse de volta para a roda? E se apresentasse um cartão de CA, convidando-o para voltar à atividade?”

Na sessão seguinte, a professora já aparece próxima ao estudante e inicia o uso dos cartóes de CA para comunicar sobre a rotina do dia. Durante a formação, analisamos o quanto é importante a interação entre os estudantes e as professoras, o quanto é preciso interagir com os alunos com TEA, e que não basta a utilização dos cartôes de CA de maneira mecânica, mas de forma dialógica e interativa. 
Em um outro momento trazido para o diálogo com a professora $\mathrm{B}$ foi a respeito da pouca interação da professora do núcleo comum - NC - com o estudante com TEA. Em um momento de roda, em que se discutia sobre sementes (tema do ano de escolaridade), o estudante pegou uma semente que estava no centro da roda e foi repreendido pela professora do NC. Não era o momento de pegar a semente, segundo a professora. Dialogou-se sobre esse fato. Ora, se ele pega a semente, está demonstrando interesse pela aula que está sendo ministrada. Por que não dar atenção a esse gesto, ou seja, a essa ação do estudante? Por que não aproveitar esse momento para uma aproximaçáo entre eles e uma interação entre a aula dada para todos os alunos?

Foram muitas açôes trazidas para o diálogo e para a reflexão. $\mathrm{O}$ cotidiano da escola, muitas vezes, distancia-nos da prática docente reflexiva. Proporcionar esse momento de observação, diálogo e autoavaliação nem sempre é possível. Por isso, verificou-se e compreendeu-se a formação continuada mediante o uso da autoscopia orientada como algo positivo e necessário nos espaços escolares. Tais dados corroboram os apresentados por Schmidt et al. (2019) ao descreverem o impacto da autoscopia quando os professores percebem como os procedimentos adotados podem contribuir para o desenvolvimento profissional. Os autores ainda destacam a importância do treinamento com base no processo de autoanálise e autoavaliação, proporcionando aos professores o desejo de reavaliar suas técnicas pedagógicas pelo confronto criado entre a observação dos vídeos e o cotidiano das experiências da sala de aula.

Observou-se que a formação continuada com a autoscopia provocou mudanças na prática pedagógica das professoras. Esses diálogos proporcionaram algumas estratégias de ensino que contribuíram para o início do uso dos cartôes de Comunicação Alternativa, tendo a fase 1 do PECS-Adaptado aprendida pelos estudantes com TEA, pelo menos até o presente momento dos dados aqui apresentados. 
No final da formação, a professora A conseguiu iniciar a fase 1 do PECS-Adaptado no momento do lanche. O estudante Júlio compreendeu que era preciso comunicar-se com a professora, entregando o cartáo de CA, para solicitar seu biscoito, e, assim, foi possível verificar essa interação, e não demonstrou nervosismo e/ou ansiedade. A professora B passou a utilizar os cartóes de CA para explicar a rotina para Marcos e também para os momentos de utilização do computador.

A fase 1 do PECS-Adaptado foi iniciada, e as professoras tinham a intenção de dar continuidade às outras fases do programa de CA. Com a formaçáo, pretende-se que as professoras do $\mathrm{AEE}$ contribuam para a formação das outras professoras do núcleo comum no uso da CA, dada a participação de todas as professoras especialistas na formação. No estudo desenvolvido por Walter e Nunes (2013), foi observado que as professoras que participaram da formação no uso do PECS-Adaptado passaram a ensinar outros professores de suas escolas a utilizarem a CA, transformando-se em multiplicadoras no ensino do uso da CA.

Em outubro de 2019, as professoras participantes da pesquisa compartilharam sobre o curso de formação em uma extensão universitária da UERJ e puderam apresentar para aproximadamente 100 pessoas o que elas tinham aprendido no curso de formação e no uso da autoscopia, além de apresentar os materiais produzidos durante o curso. Tal experiência valorizou muito a participação das profissionais na pesquisa, que puderam compartilhar com outros suas experiências e desafios no processo de formação continuada.

Como resultado também do curso de formaçáo, foi construído um mural com pranchas de cartóes de CA na sala do AEE, para outros estudantes com TEA e outros alunos com Síndrome de Down, que não participaram da pesquisa, mas demonstraram interesse pelo uso dos cartôes de CA. 
Figura 1 - Pranchas de CA disponíveis na sala de Recursos Multifuncionais do AEE

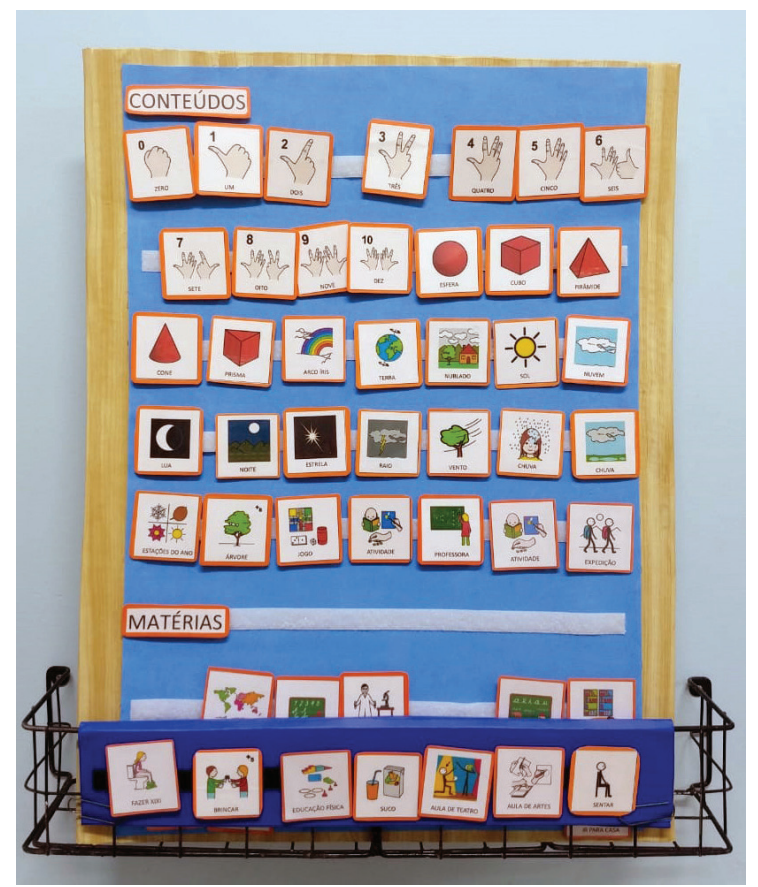

Fonte: Arquivo pessoal.

Com essa formaçáo docente e com o uso da autoscopia, foi possível que cada professora tomasse consciência de algumas lacunas em suas açóes, podendo realizar a autoconfrontaçáo e a autoavaliação, juntamente com a pesquisadora.

A literatura tem mostrado eficácia no uso da autoscopia na formação de professores com alunos com TEA, assim como tem gerado mudanças de práticas pedagógicas e motivação para formar professores multiplicadores.

Segundo Freire (1997), a aprendizagem requer a humildade de reconhecer que "não existe ensinar sem aprender". Essas açôes 
são interligadas, de modo que aquele que ensina encontra-se em processo de constante aprendizagem.

De um lado, porque identifica um conhecimento antes aprendido e, de outro, porque, observando a maneira como a curiosidade do aluno aprendiz trabalha para apreender o ensinando-se, sem o qual náo o aprende, o ensinante se ajuda a descobrir incertezas, acertos, equívocos (Freire, 1997, p. 19).

Já a pesquisa desenvolvida por Rosa-Silva et al. (2010) revela que a fase pós-ativa da autoscopia possibilita a aprendizagem reflexiva, uma vez que aperfeiçoa a competência docente, a fim de que o profissional resolva as situaçóes educativas, estando alerta, estruturando, questionando, reestruturando e planificando açóes em sala de aula.

Nunes (2016) refere-se à autoscopia como uma intervenção de cunho colaborativo, e tem uma marca dialógica que contribui para a reflexáo do professor e a reestruturaçáo da sua sala de aula.

Dessa maneira, percebe-se o quanto a autoscopia interfere positivamente na formação de professores e o quanto se faz necessário multiplicar essa técnica por meio de pesquisas baseadas em evidências para o favorecimento de mudanças na reflexão e nas práticas pedagógicas dos professores.

Foi possível observar que o PECS-Adaptado pode ser utilizado por todos os professores, tanto do AEE quanto do núcleo comum e seus familiares. Dado que corrobora os resultados obtidos por Walter (2009) ao afirmar que a Comunicação Alternativa deve estar presente em todos os contextos para que as pessoas com TEA possam se comunicar de forma clara na escola e em suas casas.

De acordo com Nunes (2008), a colaboração entre professores e educadores favorece a implementação de práticas pedagógicas empiricamente validadas. As pesquisas revelam o quanto a Comunicação Alternativa se mostra eficaz e promissora para o desenvolvimento da comunicação e da interaçáo com professores e pares. 
132 Autoscopia: uma ação reflexiva sobre a prática docente

\section{Consideraçóes finais}

Assim, entende-se o quanto a autoscopia com as professoras, acompanhada de uma pesquisadora, contribui para uma conscientização global da ação pedagógica e, portanto, da observação do próprio desempenho. Isso gera reflexão sobre a ação e mudanças na prática docente.

Verificou-se ainda a necessidade de investir na formação continuada dos professores no uso da Comunicação Alternativa de uma maneira prática e reflexiva. E essa formação não se dá apenas com as professoras do AEE, mas também com as de núcleo comum. Ressalta-se o quanto a formação in loco contribui para implementar as estratégias de ensino no ambiente onde ocorrem as interações.

Estudantes sem fala funcional são prejudicados na vida escolar por não serem compreendidos e são associados à deficiência intelectual pela dificuldade de comunicação por meio da fala. Se os espaços escolares, e sobretudo os professores, utilizarem os sistemas alternativos de comunicação, muitas barreiras serão superadas e os estudantes poderão dialogar com todos ao seu redor.

\section{Referências}

BARROS, Marta Silene Ferreira e MORAES, Silvia Pereira Gonzaga de. "Formação de Professores: expressão da complexidade da prática pedagógica”. In MACIEL, Lizete Shizue Bhomura et al. (orgs.). Formação de Professores e Prática Pedagógica, cap. 2. Maringá: Eduem, 2002, pp.15-31.

BERSCH, Rita. "Tecnologia assistiva”. In SCHIRMER, Carolina Rizzotto (org.). Atendimento Educacional Especializado: deficiência física, v. 1. São Paulo: MEC/SEEPS, 2007, v. 1, pp. 31-7.

FAGUNDES, Antônio. Descrição, definição e registro de comportamentos. Sáo Paulo: Edicon, 2000.

FIGUEIREDO, Rita Vieira de. "Incluir não é inserir, mas interagir e contribuir". Inclusão: Revista da Educação Especial, v. 5, n. 2, Brasília/DF, 2010.

FREIRE, Paulo. Professora sim, tia não: cartas a quem ousa ensinar. São Paulo: Olho d'Água, 1997. 
GATTI, Bernadete Angelina. "A formação dos docentes: o confronto necessário professor x academia”. Cadernos de Pesquisa, n. 81, São Paulo, maio 1992.

LEITE, Sérgio Antônio da Silva. "Afetividade nas práticas pedagógicas". Temas em Psicologia, v. 20, n. 2, pp. 355-68, São Paulo, 2012.

LONGAREZZI, Andrea Maturano et al. A unidade teoria e prática no contexto da formação de professores. 2007. Disponível em: http://www.revistas.uniube. br/index.php/rpd/article/view/248. Acesso em: 15 dez. 2019.

MAGALHÃES, Maria Cecília Camargo (org.). A formação do professor como um profissional crítico: linguagem e reflexão. Campinas: Mercado de Letras, 2009.

MARÇAL-GUTHIERREZ, Carla Cordeiro. "Experiências sobre um programa de professores no uso da Comunicação Alternativa e Ampliada". In et al. Práticas e perspectivas do ensino colaborativo. Rio de Janeiro: CAP/ UERJ, 2019.

MORAES, Silvia Pereira Gonzaga (orgs.). Formação de Professores e Prática Pedagógica, cap. 2. Maringá: Eduem, 2002, pp. 15-31.

NÓVOA, Antonio. Para uma formação de professores construída dentro da profissão. Disponível em: http://www.revistaeducacion.mec.es/re350/re350_09. Acesso em: 25 jul. 2016.

. A Universidade em tempos de crise. Palestra proferida na Universidade do Estado do Rio de Janeiro para professores, alunos e funcionários. Rio de Janeiro, 14 jun. 2016.

NUNES, Débora Regina. "AAC: interventions for autism: a research summary". International Journal of Special Education, v. 23, pp.17-26, 2008.

NUNES, Debora Regina de Paula e WALTER, Elizabeth Cynthia. "Processos de leitura em educandos com Autismo: um estudo de revisão". Revista Brasileira de Educação Especial, Marília, v. 22, n. 4, out.-dez. 2016.

NUNES, Leila Regina. Dando a voz através de imagens: comunicação alternativa para alunos com deficiência. Relatório CNPQ, 2007.

. Formação inicial e continuada de professores comprometida com a inclusão educacional do aluno com deficiência do ensino fundamental à universidade. Capes, 2009.

. "A prática pedagógica de mediadoras de alunos com deficiência física e dificuldades na comunicaçáo em escola do Rio de Janeiro". In GLAT, R. e PLETSCH, M. R. (org.). Estratégias educacionais diferenciadas para alunos com necessidades especiais. Rio de Janeiro: EdUERJ/Proesp, 2013.

PEREIRA, Júlio Emílio Diniz. "A pesquisa dos educadores como estratégia para a construção de modelos críticos de formação docente". In $\mathrm{e}$ ZEICHNER, Kenneth (orgs.). A pesquisa na formação e no trabalho docente. Belo Horizonte: Autêntica, 2002, pp. 67-94. 
134 Autoscopia: uma ação reflexiva sobre a prática docente

ROSA-SILVA, Patrícia de Oliveira et al. "A autoscopia como estratégia da sala de espelhos na formaçáo continuada de uma professora de ciências". Anais do VII Encontro Nacional em Pesquisa em Educação em Ciências. Florianópolis, nov. 2009. Disponível em: http://www.posgrad.fae.ufmg.br/posgrad/ viienpec/pdfs/1430.pdf.

et al. "Análise das reflexôes da professora de ciências sobre sua relação com os alunos e implicaçôes para a prática educativa”. Revista Ensaio, v. 12, n. 1, pp. 63-82, Belo Horizonte, jan.-abr. 2010.

SADALLA, Ana Maria Falcão de Aragáo e LAROCCA, Priscila. "Autoscopia: um procedimento de pesquisa e de formação". Educação e Pesquisa, v. 30, n. 3, pp. 419-33, São Paulo, set.-dez. 2004.

SCHIRMER, Carolina Rizzoto. Comunicação alternativa e formação inicial de professores para a escola inclusiva (tese). Universidade do Estado do Rio de Janeiro, 2012.

SCHMIDT, Carlo et al. "Autoscopy as a methodological resource in the interventions with autism: empirical aspects". Psicologia: Teoria e Prática, v. 21, n. 3, pp. 418-36.

SILVA, Thatyana Machado. A Autoscopia como ferramenta para a formação continuada de professores de Sala de Recursos Multifuncionais (tese). Universidade do Estado do Rio de Janeiro, 2016.

TOGASHI, Claudia Miharu et al. "A importância da formaçáo continuada para ampliar os conhecimentos dos professores do Atendimento Educacional Especializado em Comunicação Alternativa e Ampliada”. In NUNES, L. R. O. P. e SCHIRMER, C. R. (orgs.). Salas Abertas: formação de professores e práticas pedagógicas em Comunicação Alternativa e Ampliada nas Salas de Recurso Multifuncionais. Rio de Janeiro: EdUERJ, 2017.

WALTER, Catia Crivelenti de Figueiredo. Os efeitos da adaptação do PECS ao Curriculum Funcional Natural em pessoas com autismo infantil (dissertaçáo). Universidade Federal de São Carlos, 2000.

. "Comunicaçáo Alternativa para pessoas com autismo: o que as pesquisas revelam sobre o uso do PECS-Adaptado por pessoas com autismo". In DELIBERATO, Débora et al. Comunicação Alternativa: teoria, prática, tecnologia e pesquisa. São Paulo: Memnon Ediçōes Científicas, 2009, pp. 96-106.

e NUNES, Leila Regina. "Comunicação alternativa para alunos com Autismo no ensino regular". Revista Educação Especial, v. 26, n. 47, pp. 587602, Santa Maria, set.-dez. 2013. 